\title{
The impact of intervention to the incidence of natural focus diseases during the outbreak of COVID-19 in Jiangsu Province, China
}

\section{Xiaoqing Cheng}

Jiangsu Province Center for Disease Control and Prevention

Jianli Hu

Jiangsu Province Center for Disease Control and Prevention

Li Luo

Xiamen University School of Public Health

Zeyu Zhao

Xiamen University School of Public Health

Nan Zhang

Jiangsu Province Center for Disease Control and Prevention

Mikah Ngwanguong Hannah

Xiamen University Medical College

Jia Rui

Xiamen University School of Public Health

Shengnan Lin

Xiamen University School of Public Health

Yuanzhao Zhu

Xiamen University School of Public Health

\section{Yao Wang}

Xiamen University School of Public Health

\section{Meng Yang}

Xiamen University School of Public Health

Jingwen Xu

Xiamen University School of Public Health

Xingchun Liu

Xiamen University School of Public Health

\section{Tianlong Yang}

Xiamen University School of Public Health

Weikang Liu

Xiamen University School of Public Health

\section{Peihua Li}


Xiamen University School of Public Health

\section{Bin Deng}

Xiamen University School of Public Health

\section{Zhuoyang Li}

Xiamen University School of Public Health

\section{Chan Liu}

Xiamen University School of Public Health

\section{Jiefeng Huang}

Xiamen University School of Public Health

Changjun Bao ( $\square$ bao2000_cn@163.com )

Jiangsu Province Center for Disease Control and Prevention

Tianmu Chen ( $\sim$ 13698665@qq.com)

Xiamen University School of Public Health https://orcid.org/0000-0003-0710-5086

\section{Research Article}

Keywords: Doxorubicin, crocin, apoptosis, oxidative stress, myocardial toxicity

Posted Date: May 11th, 2021

DOl: https://doi.org/10.21203/rs.3.rs-476224/v1

License: (c) (i) This work is licensed under a Creative Commons Attribution 4.0 International License. Read Full License 


\section{Abstract}

Doxorubicin (DOX) is a well-known chemotherapeutic drug for most malgnencies including breast cancer and leukemia whilst the usage of DOX is limited owing to its cardiotoxicity. The present study analyzed the effects of crocin on doxorubicin's cardiotoxic efect in rat myocardium and searched their mechanistic interaction in the pathogenesis of DOX-induced myocardial toxicity. Forty rats were divided into four groups; (a) control (received normal saline as a dose of $1 \mathrm{ml} / \mathrm{kg}$ by ip for 15 days), (b) Crocin (received crocin as a dose of $40 \mathrm{mg} / \mathrm{kg} / 24 \mathrm{~h}$ by ip for 15 days), (c) DOX (received DOX as a dose of $2 \mathrm{mg} / \mathrm{kg} / 48 \mathrm{~h}$ by ip in six injection, cumulative dose $12 \mathrm{mg} / \mathrm{kg}$ ), and (d) DOX+Crocin (received DOX as a dose of 2 $\mathrm{mg} / \mathrm{kg} / 48 \mathrm{~h}$ by ip in six injection and crocin as a dose of $40 \mathrm{mg} / \mathrm{kg} / 24 \mathrm{~h}$ ip for 15 days). According to the present study, DOX administration caused significant increases in lipid indices (triglyseride, low-dencity lipoproteins and very low-dencity lipoproteins) as well as cardiac markers (Creatine kinase-muscle/brain and Cardiac Troponin I). Morever, DOX caused significant increases in oxidative stress parameters (malondialdehyde and total oxidant status) as well as decreases in antioxidant defense systems (glutathione, superoxide dismutase, catalase and total antioxidant status). The present study also demonstrated that co-administration of crocin with DOX significantly ameliorated the lipid profile and biochemical parameters in rats receiving DOX. The results were supported by histopathological and immunohistochemical evaluations. Taken together, our results reveal that crocin might be a cardioprotective agent in DOX treated patients for cancer.

\section{Introduction}

Corona Virus disease 2019 (COVID-19) was first detected in Wuhan, Hubei Province of China in December 2019[1, 2]. The movement of people between Jiangsu and Hubei Provinces led to the massive burden in controlling COVID-19 epidemic in Jiangsu Province[3], on January 22, 2020, the first confirmed case of COVID-19 was found in Jiangsu[4], soon followed by an outbreak of 684 cases as of Dec 31. Government actively respond to the outbreak of COVID-19 with some countermeasures, including lockdown, travel restrictions, suspension of work and so on $[5,6]$.

Several studies have shown that corresponding prevention and control measures were effective in controlling the increase of COVID-19 cases[7, 8, 9], including travel restrictions, restrict population movement, suspension of work and so on. However, these interventions also influenced the surveillance and spread of other infectious diseases[10, 11], including the natural focus diseases[12, 13]. A study in Japan showed that seasonal influenza activity in the country was lower than in previous years due to COVID-19 outbreak in 2020[14]. Another study found that the implementation of the social distance led to an increase in dengue cases in Thailand[15]. Therefore, there is no consistent research result on the impact of COVID-19 interventions on other infectious diseases.

Autoregressive Integrated Moving Average(ARIMA) model is one of infectious disease prediction models[16, 17], which can be used to fit seasonal and non-seasonal time series, called seasonal ARIMA model and non-seasonal ARIMA model. In this study, we established an ARIMA model based on the 
reported incidence from 2015 to 2019, and predicted the incidence in 2020, compared the predicted incidence with the reported incidence, and then explored the impact of COVID-19 on routine surveillance of natural focus diseases during COVID-19 outbreak in Jiangsu Province. In this study we aimed at providing scientific evidences for the prevention and control of natural focus diseases during COVID-19.

\section{Method}

\section{Study area}

Jiangsu, in the eastern province of China, with an area of 40,000 square miles and a population of about 80 million (ranked fifth most populated amongst the provinces in China). As of December 31, 2020, Jiangsu Province had more than 600 confirmed cases of COVID-19, and several studies reported the presence of different types of natural focus diseases in Jiangsu province[18, 19, 20, 21], At present, Jiangsu Province has not published an article about the impact of COVID-19 on natural focus disease. Therefore, it is of great value to find the impact of COVID-19 on routine surveillance of natural focus diseases.

\section{Data collection}

We collected the reported cases of natural focus diseases (brucellosis, malaria, hemorrhagic fever with renal syndrome[HFRS], dengue, Severe Fever With Thrombocytopenia Syndrome[SFTS], Rabies, Tsutsugamushi and Japanese encephalitis [JE]) from 2015-2020 and data of the confirmed COVID-19 patients from January 22, 2020 to December 31, 2020 in Jiangsu Province by referring to the Health Records of Jiangsu Provincial Center for Disease Control and Prevention (Jiangsu Provincial CDC). The confirmed patients of COVID-19 were diagnosed based on the criterion of World Health Organization (WHO) interim guidance[22]. This study was approved by the Ethical Committee of Jiangsu provincial CDC. All data analyzed were anonymized.

\section{ARIMA model fitting and prediction}

Due to the seasonal characteristics of natural focus diseases in Jiangsu Province (except for dengue), $\operatorname{ARIMA}(p, d, q) \times(P, D, Q) s$ was adopted for natural focus diseases( $\operatorname{ARIMA}(p, d, q)$ model was adopted for dengue). Use the autocorrelation and partial autocorrelation features to identify the model, test the significance of the established model parameters, and analyze the residuals between the value of model fitted and reported, make ACF diagrams and PACF diagrams for the residual sequence, and use the BoxLjung residual white noise test method to determine whether the residual sequence is a white noise sequence, if $P \otimes 0.05$, then residual is a white noise sequence, indicated that the established model is suitable and can be used for prediction.

\section{Statistical analysis}

The data were entered in Microsoft Excel 2019 (Microsoft Crop., USA). Nonparametric tests were used to analyze the difference between the reported incidence and the predicted incidence in 2020, difference 
between reported incidence in 2020 and previous four years, difference between the duration from illness onset date to diagnosed date(DID) in 2020 and the previous four years. The determination coefficient $\left(R^{2}\right)$ was used to evaluate the goodness of fit of the model simulation, regression analysis was used to calculate $R^{2}$. Statistical analyses and establishment of ARIMA model were conducted with SPSS 13.0 software (IBM Corp., Armonk, NY, USA), and GraphPad Prism 7.0 (GraphPad Software, La Jolla, CA).

\section{Results}

\section{The incidence trend and curve fitting results of natural focus disease}

Natural focus diseases in Jiangsu Province have a long-term seasonality trend. The incidence of natural focus disease was high between September and December each year, with an increasing trend from September and a decreasing trend after reaching its peak in November (Fig. 1-A).

The ARIMA $(1,0,0)(0,1,0)_{12}$ model was adopted under comprehensive considerations including model parameter test, white noise test $\$ Table 1 \and $95 \%$ confidence interval $(\mathrm{Cl}) . R^{2}=0.795, P \otimes 0.05$, indicating that the model fitted the incidence from 2015 to 2019 well, and could be used to predict incidence of natural focus of disease in Jiangsu Province in 2020. From the prediction results in Figure 1-A, it could be seen that the reported incidence in 2020 was lower than the predicted incidence, and the difference was statistically significant $(U=31, P \otimes 0.05)$ 
Table 1

ARIMA model parameters and white noise test of natural focus diseases, malaria, SEFS and dengue.

\begin{tabular}{|c|c|c|c|c|c|c|c|c|}
\hline \multirow[t]{2}{*}{ Disease } & \multicolumn{6}{|c|}{ Model and parameter test } & \multicolumn{2}{|c|}{$\begin{array}{l}\text { White noise } \\
\text { test }\end{array}$} \\
\hline & Model & parameter & Estimates & $\begin{array}{l}\text { Std } \\
\text { Error }\end{array}$ & $t$ & $P$ & $\begin{array}{l}\text { Box- } \\
\text { Ljung }\end{array}$ & $P$ \\
\hline \multirow{3}{*}{$\begin{array}{l}\text { Natural } \\
\text { focal } \\
\text { disease }\end{array}$} & ARIMA & AR & 0.438 & 0.132 & 3.326 & $<0.05$ & 0.185 & 0.667 \\
\hline & $\begin{array}{l}(1,0,0) \\
(0,1,0)_{12}\end{array}$ & $\begin{array}{l}\text { Non-Seasonal } \\
\text { lag } 1\end{array}$ & & & & & & \\
\hline & & $\begin{array}{l}\text { Seasonal } \\
\text { difference }\end{array}$ & 1 & & & & & \\
\hline \multirow[t]{7}{*}{ Malaria } & ARIMA & AR & 0.97 & 0.05 & 19.01 & $<0.05$ & 0.089 & 0.765 \\
\hline & $(1,0,1)_{12}$ & $\begin{array}{l}\text { Non-Seasonal } \\
\text { lag } 1\end{array}$ & & & & & & \\
\hline & & MA & 0.79 & 0.12 & 6.37 & $<0.05$ & & \\
\hline & & $\begin{array}{l}\text { Non-Seasonal } \\
\text { lag } 1\end{array}$ & & & & & & \\
\hline & & AR & -0.44 & 0.14 & -3.18 & $<0.05$ & & \\
\hline & & $\begin{array}{l}\text { Seasonal lag } \\
1\end{array}$ & & & & & & \\
\hline & & $\begin{array}{l}\text { Seasonal } \\
\text { difference }\end{array}$ & 1 & & & & & \\
\hline \multirow[t]{5}{*}{ SFTS } & ARIMA & AR & 0.78 & 0.21 & 3.67 & $<0.05$ & 0.304 & 0.581 \\
\hline & $\begin{array}{l}(0,1,1) \\
(1,0,0)_{12}\end{array}$ & $\begin{array}{l}\text { Non-Seasonal } \\
\text { lag } 1\end{array}$ & & & & & & \\
\hline & & AR & 0.98 & 0.22 & 4.47 & $<0.05$ & & \\
\hline & & $\begin{array}{l}\text { Non-Seasonal } \\
\text { lag } 1\end{array}$ & & & & & & \\
\hline & & $\begin{array}{l}\text { Non-Seasonal } \\
\text { difference }\end{array}$ & 1 & & & & & \\
\hline \multirow[t]{2}{*}{ Dengue } & ARIMA & MA & 0.44 & 0.12 & 3.70 & $<0.05$ & 1.171 & 0.279 \\
\hline & $(1,1,1)$ & $\begin{array}{l}\text { Non-Seasonal } \\
\text { lag } 1\end{array}$ & & & & & & \\
\hline
\end{tabular}

ARIMA Autoregressive Integrated Moving Average, AR Autoregressive, MA Moving Average, HFRS Hemorrhagic fever with renal syndrome, SFTS Severe Fever With Thrombocytopenia Syndrome, JE Japanese encephalitis 


\begin{tabular}{lllll} 
AR & 0.64 & 0.11 & 6.02 & $<0.05$ \\
$\begin{array}{l}\text { Seasonal lag } \\
1\end{array}$ & & & & \\
$\begin{array}{l}\text { Non-Seasonal } \\
\text { difference }\end{array}$ & 1 & & & \\
\hline
\end{tabular}

ARIMA Autoregressive Integrated Moving Average, AR Autoregressive, MA Moving Average, HFRS Hemorrhagic fever with renal syndrome, SFTS Severe Fever With Thrombocytopenia Syndrome, JE Japanese encephalitis

\section{The monthly distribution of natural focus disease}

The monthly incidence in 2020 was compared with the year from 2015 to 2019 (Figure 2). The results showed that the incidence of brucellosis in July, August September and November 2020 (Figure 2-A), SFTS in April to November 2020 were higher than the same period in the previous four years (Figure 2-D) $(P \otimes 0.05)$. The incidence of malaria in April to December 2020 (Figure 2-B), HFRS in March, April and December 2020 (Figure 2-C), dengue in July to November 2020 were lower than the same period in the previous four years (Figure 2-E) (P冈0.05). No statistically significant differences were found in other natural focus diseases.

\section{The incidence trend and curve fitting results of Malaria, SFTS and dengue}

The incidence of malaria and SFTS in Jiangsu Province have a long-term trend and seasonality. The incidence of dengue was relatively low in 2015-2017, and has increased since 2018. The peak incidence in 2018 and 2019 were concentrated in June to October.

As for malaria, the ARIMA $(1,0,1)(1,1,0)_{12}$ model was adopted under comprehensive considerations including model parameter test, white noise test $₫$ Table 1 \and $95 \% \mathrm{Cl} . R^{2}=0.365, P \otimes 0.05$, indicating that the model fitted the incidence from 2015 to 2019 well, and could be used to predict incidence of malaria in Jiangsu Province in 2020. From the prediction results in Figure 1-B, it could be seen that the reported incidence in 2020 was lower than predicted incidence, and the difference was statistically significant $(U=14, P \otimes 0.05)$.

As for SFTS, the ARIMA $(0,1,1)(1,0,0)_{12}$ model was adopted under comprehensive considerations including model parameter test, white noise test $₫$ Table 1 \and $95 \% \mathrm{Cl} . R^{2}=0.454, P \otimes 0.05$, indicating that the model fitted the incidence from 2015 to 2019 well, and could be used to predict incidence of SFTS in Jiangsu Province in 2020. From the prediction results in Figure 1-C, it could be seen that the reported incidence in 2020 was higher than predicted incidence, but the difference was not statistically significant $(U=68, P \otimes 0.05)$

As for dengue, the ARIMA $(1,1,1)$ model was adopted under comprehensive considerations including model parameter test, white noise test $\$ Table $1 \rrbracket$ and $95 \% \mathrm{Cl} . R^{2}=0.774, P \otimes 0.05$, indicating that the model 
fitted the incidence from 2015 to 2019 well, and could be used to predict incidence of dengue in Jiangsu Province in 2020. From the prediction results in Figure 1-D, it could be seen that the reported incidence in 2020 was lower than predicted incidence, and the difference was statistically significant $(U=1, P \otimes 0.05)$

\section{The gender distribution of natural focus diseases}

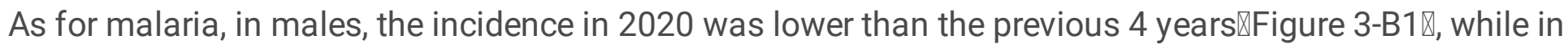
females, the incidence in 2020 was lower than 2016 (Figure 3-B2), and the difference were statistically significant ( $P \otimes 0.05)$. As for SFTS, in females, the incidence in 2020 was higher than 2015 (Figure 3-D2), and the difference was statistically significant $(P \otimes 0.05)$. As for dengue, in males, the incidence in 2020 was lower than 2017, 2018 and 2019 (Figure 3-E1), and the difference were statistically significant (P] 0.05). The incidences of other natural focus diseases in males and females in 2020 were not statistically different from the previous four years $(P \otimes 0.05)$.

\section{The age distribution of brucellosis, malaria and HF of natural focus diseases}

As for malaria, in the age group 20-60 years, the incidence in 2020 was lower than the previous four years (Figure 4-B2 and Figure 4-B3), and the difference were statistically significant (Pख0.05).

As for SFTS, in the age group 40-60 years, the incidence in 2020 was higher than 2015 and 2018 (Figure 4-D3), in the age group $\geq 60$ years, the incidence in 2020 was higher than 2015 (Figure 4-D4), and the difference were statistically significant $(P \otimes 0.05)$.

As for dengue, in the age group 20-40 years, the incidence in 2020 was lower than 2018 and 2019 (Figure 4-E2), in the age group 40-60 years, the incidence in 2020 was lower than 2016, 2017 and 2018 (Figure 4$\mathrm{E} 3)$, and the difference were statistically significant $(P \otimes 0.05)$.

The incidences of other natural focus diseases in each age group in 2020 were not statistically different from the previous four years $(P \otimes 0.05)$.

\section{Urban and rural distribution of natural focus diseases}

As for brucellosis (Figure 5-A1), in urban, the number of cases in 2020 was higher than 2015, 2016 and 2019 , and the difference was statistically significant ( $P \otimes 0.05)$.

As for malaria (Figure 5-B1 and Figure 5-B2), in both urban and rural, the number of cases in 2020 were lower than the previous four years, and the difference was statistically significant ( $P \otimes 0.05)$.

The number of cases of other natural focus diseases in urban and rural in 2020 were not statistically different from the previous four years $(P \otimes 0.05)$.

\section{Distribution of the DID for natural focus diseases}


The DID in 2020 was compared with the previous four years. The results showed that the DID of brucellosis and SFTS in 2020 was shorter than 2015-2018; the DID of Tsutsugamushi in 2020 was shorter than the previous four years, and the difference were statistically significant (P凶0.05). The DID of other natural focus diseases in 2020 were not statistically different from previous four years $(P \otimes 0.05)$ (Table 2).

Table 2

Distribution of duration from illness onset date to diagnosed date for natural focus diseases, Jiangsu Province, China, 2015-2020

\begin{tabular}{|c|c|c|c|c|c|c|c|c|}
\hline \multirow[t]{2}{*}{ Year } & \multicolumn{8}{|c|}{ Median (IQR)(days) } \\
\hline & Brucellosis & Malaria & HFRS & SFTS & Dengue & Rabies & Tsutsugamushi & JE \\
\hline 2015 & $16(7-35)^{\star}$ & $2(1-4)$ & $\begin{array}{l}6(4- \\
9)\end{array}$ & $\begin{array}{l}12(8- \\
16)^{\star}\end{array}$ & $5(3-7)$ & $\begin{array}{l}3(2- \\
4)\end{array}$ & $5(2-9) *$ & $\begin{array}{l}24(7- \\
42)\end{array}$ \\
\hline 2016 & $17(4-31)^{\star}$ & $3(2-5)$ & $\begin{array}{l}6(4- \\
10)\end{array}$ & $\begin{array}{l}14(9- \\
19)^{\star}\end{array}$ & $\begin{array}{l}6(4- \\
14)\end{array}$ & $\begin{array}{l}3(2- \\
5)\end{array}$ & $5(2-9)$ * & $\begin{array}{l}38(11- \\
56)\end{array}$ \\
\hline 2017 & $15(7-30)^{\star}$ & $3(2-6)$ & $\begin{array}{l}6(4- \\
10)\end{array}$ & $\begin{array}{l}11(7- \\
20)^{\star}\end{array}$ & $7(5-9)$ & $\begin{array}{l}3(2- \\
5)\end{array}$ & $6(3-9) *$ & $\begin{array}{l}29(18- \\
79)\end{array}$ \\
\hline 2018 & $10(4-27)^{\star}$ & $3(2-5)$ & $\begin{array}{l}7(3- \\
11)\end{array}$ & $\begin{array}{l}9(7- \\
14)^{\star}\end{array}$ & $\begin{array}{l}7(4- \\
10)\end{array}$ & $\begin{array}{l}3(2- \\
4)\end{array}$ & $6(2-9) *$ & $\begin{array}{l}76(7- \\
85)\end{array}$ \\
\hline 2019 & $8(1-16)$ & $3(2-5)$ & $\begin{array}{l}7(3- \\
10)\end{array}$ & $\begin{array}{l}8(6- \\
12)\end{array}$ & $6(4-8)$ & $\begin{array}{l}3(1- \\
6)\end{array}$ & $5(2-8) *$ & - \\
\hline 2020 & $7(1-20)$ & $3(2-5)$ & $\begin{array}{l}6(2- \\
11)\end{array}$ & $\begin{array}{l}8(4- \\
12)\end{array}$ & $\begin{array}{l}6(4- \\
10)\end{array}$ & $\begin{array}{l}5(3- \\
6)\end{array}$ & $5(2-8)$ & $\begin{array}{l}9(8- \\
10)\end{array}$ \\
\hline \multicolumn{9}{|c|}{$\begin{array}{l}\text { IQR inter-quartile range, HFRS Hemorrhagic fever with renal syndrome, SFTS Severe Fever With } \\
\text { Thrombocytopenia Syndrome, JE Japanese encephalitis }\end{array}$} \\
\hline
\end{tabular}

\section{Discussion}

A kind of pneumonia of unknown cause occurred in Wuhan, Hubei, China in December 2019[23], and was named COVID-19 on February 11[24] by the WHO. Following the confirmation of the first case of COVID19 in Jiangsu Province, the provincial government has been striving and focusing on epidemic prevention and control. Appropriate countermeasures including restriction of population mobility, lockdown and so on have been taken, thus the number of daily confirmed new cases peaked and then declined rapidly over time in Jiangsu Province[25]. It indicated that the public preventive measures in limiting transmission of COVID-19 were highly effective. Moreover, these measures also had an impact on other diseases[26, 27, 28].

In this study, we established ARIMA model to fit the incidence of natural focus diseases, comprehensive consideration of various factors to select the optimal model, and then used the optimal model to 
predicted incidence in 2020. Our research results found that the reported incidence of natural focus diseases (including brucellosis, malaria, HFRS, dengue, SFTS, Rabies, Tsutsugamushi and JE) in 2020 was lower than the predicted incidence, the differences was statistically significant. Although we could not directly evaluate the effect of each measure, restriction of population mobility would by far be among the most influential methods for the reduction in natural focus diseases transmission. We also found that the DID of brucellosis, SFTS and Tsutsugamushi in 2020 was shorter than before, indicating that during the outbreak of COVID-19, the surveillance efficiency of some natural focus diseases in Jiangsu Province had changed. There was also a research called that COVID-19 had caused a serious burden on the public health system of many countries, but the prevention and control measures of other diseases should not be neglected[29].

The results showed that the reported incidence of brucellosis in July, August, September and November 2020 were higher than the same period in the previous four years. A study showed that sheep/goat were the main contacted animals[30], therefore, the reason might be that in the second half of 2020, with the resumption of work and production, pastoralists had more opportunities to contact with livestock, thus the probability of infection increased. The reported incidence of SFTS in April to November 2020 were higher than the same period in the previous four years, while the reported incidence of malaria in April to December 2020, dengue in July to November 2020 were lower than the same period in the previous four years, In addition, the incidence of malaria and SFTS in 2020 had a huge change compared with the incidence in the previous years. The incidence of dengue had an upward trend in 2015-2019, but it dropped in 2020. Therefore, we modeled malaria, SFTS and dengue separately. By building an ARIMA model, the results showed that the reported incidence of malaria and dengue in 2020 were lower than predicted incidence, and the difference were statistically significant. As for malaria, our finding was inconsistent with the studies in other areas or countries[31]. The reason might be that malaria was predominantly endemic in these countries and was mainly caused by the bite of anopheles mosquitoes, but in Jiangsu Province, most malaria cases were imported cases from abroad[32]. The "Infectious Disease Surveillance System" of Chinese CDC shows that the cases of dengue in Jiangsu Province were all the imported cases from abroad. During the outbreak of COVID-19 in China, the main nonpharmacological interventions, such as lockdown, travel restrictions, keeping social distance, suspension of work and production and wearing masks were applied. Interventions which can affect natural focus diseases consisting of lockdown, travel restriction and suspension of work and production. For example, travel restrictions could directly reduce the reported cases of dengue and malaria, since the most cases of malaria and dengue in Jiangsu were imported cases. Furthermore, suspension of work and production might lead to the reduction in reported cases of brucellosis. We also found that the reported incidence of SFTS in 2020 was higher than the predicted incidence, but the difference was not statistically significant, the reason might be that the incidence of SFTS had been on the rise in 2015-2019, so the incidence itself might rise in 2020. The real reason and mechanism need to be further studied.

The results of age distribution showed that the reported incidence of malaria in age group 20-60 years was lower than the previous four years. This might be due to the fact that the most of the population entering the province from abroad were the working population, so the incidence of malaria in this age 
group was significantly affected by COVID-19 prevention and control measures. The result also showed that the reported incidence of dengue in age group 40-60 years was lower than 2016-2018. This might be due to the fact that the cases of dengue were mainly in the age group of 20-60 years, therefore, these age group were more affected by the decreased of imported cases.

Another interesting finding was that the gender distribution in our analysis showed a lower incidence of dengue in males in 2020 than 2017-2019. According to the surveillance, the incidence of dengue fever in males was much higher than females, therefore, the incidence of males was more likely to be affected by the decreased of imported cases. The incidence of malaria in males in 2020 was lower than the previous four years, too. The majority of imported malaria cases in Jiangsu were males[32], so the incidence of malaria in males in 2020 might be greatly affected by the decrease of imported cases. In addition, we found that the reported incidences of malaria in both urban and rural were lower than the previous four years. The results indicates that the incidence of malaria has been affected regardless of the overall incidence, gender distribution, age distribution, urban or rural areas.

\section{Limitation}

This study has limitations. Firstly, we limited to pinpoint the real reasons for the decrease of natural focus diseases, it may be related to: a) After the outbreak of COVID-19, the number of people who take the initiative to see a doctor may decrease, resulting in a reduction in reported incidence; $b$ ) The incidence of natural focus diseases itself had fallen. Secondly, some other factors, such as climatic factors, economic factors and so on, which might affect the spread of the disease[33,34], were not considered in this study. However, in our research, we established a model to fit the incidence of the disease from 2015 to 2019, used the optimal model to predict the incidence of 2020, and then compared the actual incidence before reaching a conclusion. Therefore, these factors mentioned above might have little influence on our conclusion.

\section{Conclusion}

The interventions for COVID-19 may have preventive effects on some natural focus diseases in Jiangsu Province. The reported incidence of natural focus diseases decreased during the outbreak of COVID-19 in 2020, especially malaria and dengue. COVID-19 prevention and control measures, such as lockdown, travel restrictions, suspension of work and production, had the greatest impact on males and people in the age group of 20-60 years. The incidence of malaria was affected regardless of the overall incidence, gender distribution, age distribution, urban and rural areas.

\section{Abbreviations}

CDC: Center for Disease Control and Prevention; SARS-CoV-2:Severe Acute Respiratory SyndromeCoronavirus 2; HFRS: hemorrhagic fever with renal syndrome; SFTS: Severe Fever With 
Thrombocytopenia Syndrome; JE: Japanese encephalitis; ARIMA: Autoregressive Integrated Moving Average

\section{Declarations}

\section{Acknowledgements}

We thank the staff members at the hospitals, local health departments, and municipal and county-level Center for Disease Control and Prevention offices for their valuable assistance in coordinating the data collection.

\section{Ethics approval and consent to participate}

This effort of disease control was part of CDC's routine responsibility in Jiangsu Province, China.

Therefore, institutional review and informed consent were not required for this study. All data analyzed were anonymized.

\section{Consent for publication}

Not applicable.

\section{Availability of data and material}

Data supporting the conclusions of this article are included within the article.

\section{Competing interests}

The authors declare that they have no competing interests.

\section{Funding}

This study was partly supported by Jiangsu Province Science \& Technology Demonstration Project for Emerging Infectious Diseases Control and Prevention (No: BE2015714), Key Medical Discipline of Epidemiology (No: ZDXKA2016008), the Bill \& Melinda Gates Foundation (INV-005834), the Science and Technology Program of Fujian Province (No: 2020Y0002), and the Xiamen New Coronavirus Prevention and Control Emergency Tackling Special Topic Program (No: 3502Z2020YJ03). The funders had no role in study design, data collection and analysis, decision to publish, or preparation of the manuscript.

\section{Authors' contributions}

TMC, CJB, LL and ZZZ designed research; JLH, LL, ZZZ, CL, JFH, ZYL, WKL, LL, PHL, TLY and XQC analyzed data, TMC, LL, ZZZ, NZ, MNH, RJ, MY, YZZ, YW, JWX, JFH, ZYL, SNL, SYL and JLH conducted the research and analyzed the results; TMC, JLH, XQC, LL and ZZZ wrote the manuscript. All authors read and approved the final manuscript. 


\section{References}

1. Wang C, Horby P, Hayden F, Gao G. A novel coronavirus outbreak of global health concern. Lancet. 2020;395 10223:470-3. doi:10.1016/s0140-6736(20)30185-9.

2. Mizumoto K, Kagaya K, Chowell G. Early epidemiological assessment of the transmission potential and virulence of coronavirus disease 2019 (COVID-19) in Wuhan City, China, January-February, 2020. BMC Med. 2020;18 1:217; doi:10.1186/s12916-020-01691-x.

3. Wu J, Leung K, Leung G. Nowcasting and forecasting the potential domestic and international spread of the 2019-nCoV outbreak originating in Wuhan, China: a modelling study. Lancet. 2020;395 10225:689-97. doi:10.1016/s0140-6736(20)30260-9.

4. Health. JCo. A confirmed COVID-19 case in Suzhou was reported by the national health and Health Commission. 2020.

5. Shen J, Duan H, Zhang B, Wang J, Ji JS, Wang J, et al. Prevention and control of COVID-19 in public transportation: Experience from China. Environ Pollut. 2020;266 Pt 2:115291; doi:10.1016/j.envpol.2020.115291. https://www.ncbi.nlm.nih.gov/pubmed/32829124.

6. Kurita J, Sugawara T, Ohkusa Y. Estimated effectiveness of school closure and voluntary event cancellation as COVID-19 countermeasures in Japan. Journal of infection chemotherapy: official journal of the Japan Society of Chemotherapy. 2020. doi:10.1016/j.jiac.2020.08.012.

7. Choi S, Ki M. Estimating the reproductive number and the outbreak size of COVID-19 in Korea. Epidemiology health. 2020;42:e2020011. doi:10.4178/epih.e2020011.

8. Ji T, Chen HL, Xu J, Wu LN, Li JJ, Chen K, et al. Lockdown Contained the Spread of 2019 Novel Coronavirus Disease in Huangshi City, China: Early Epidemiological Findings. Clin Infect Dis. 2020;71 6:1454-60; doi:10.1093/cid/ciaa390. https://www.ncbi.nlm.nih.gov/pubmed/32255183.

9. Organization WH. COVID-19 STRATEGY UPDATE. 2020;1-18.

10. Wu D, Lu J, Liu Y, Zhang Z, Luo L. Positive effects of COVID-19 control measures on influenza prevention. International journal of infectious diseases: IJID : official publication of the International Society for Infectious Diseases. 2020;95:345-6. doi:10.1016/j.ijid.2020.04.009.

11. Wu D, Lu J, Cao L, Ma X, Liu Q, Liu Y, et al. Positive effects of COVID-19 control measures on pneumonia prevention. International journal of infectious diseases: IJID : official publication of the International Society for Infectious Diseases. 2020;96:548-9. doi:10.1016/j.ijid.2020.05.069.

12. Nghochuzie N, Olwal C, Udoakang A, Amenga-Etego L, Amambua-Ngwa A. Pausing the Fight Against Malaria to Combat the COVID-19 Pandemic in Africa: Is the Future of Malaria Bleak? Frontiers in microbiology. 2020;11:1476; doi: 10.3389/fmicb.2020.01476.

13. Wilder-Smith A, Tissera H, Ooi EE, Coloma J, Scott TW, Gubler DJ. Preventing Dengue Epidemics during the COVID-19 Pandemic. Am J Trop Med Hyg. 2020;103 2:570-1; doi:10.4269/ajtmh.20-0480. https://www.ncbi.nlm.nih.gov/pubmed/32539912.

14. Cao Y, Cai K, Xiong L. Coronavirus disease 2019: A new severe acute respiratory syndrome from Wuhan in China. Acta virologica. 2020;64 2:245 - 50; doi: 10.4149/av_2020_201. 
http://www.ncbi.nlm.nih.gov/pubmed/32551792.

15. Lim J, Dickens B, Chew L, Choo E, Koo J, Aik J, et al. Impact of sars-cov-2 interventions on dengue transmission. PLoS Negl Trop Dis. 2020;14 10:e0008719. doi:10.1371/journal.pntd.0008719.

16. Liu L, Luan R, Yin F, Zhu X, Lü Q. Predicting the incidence of hand, foot and mouth disease in Sichuan province, China using the ARIMA model. Epidemiology infection. 2016;144(1):144-51. doi:10.1017/s0950268815001144.

17. Zha W, Li W, Zhou N, Zhu J, Feng R, Li T, et al. Effects of meteorological factors on the incidence of mumps and models for prediction, China. BMC Infect Dis. 2020;20 1:468; doi:10.1186/s12879-02005180-7.

18. Xiao Y, Zou G, Yin J, Tan W, Zhou J, Zhang H. Seroepidemiology of human Brucella infection in Yixing, China. Tropical doctor. 2017;47 2:165-7; doi:10.1177/0049475516640191. http://www.ncbi.nlm.nih.gov/pubmed/27079490.

19. Tan Z, Huang Y, Liu G, Zhou W, Xu X, Zhang Z, et al. A Familial Cluster of Human Brucellosis Attributable to Contact with Imported Infected Goats in Shuyang, Jiangsu Province, China, 2013. Am J Trop Med Hyg. 2015;93 4:757-60; doi:10.4269/ajtmh.15-0149. https://www.ncbi.nlm.nih.gov/pubmed/26149866.

20. Ding G, Zhu G, Cao C, Miao P, Cao Y, Wang W, et al. The challenge of maintaining microscopist capacity at basic levels for malaria elimination in Jiangsu Province, China. BMC public health. 2018;181:489; doi: 10.1186/s12889-018-5307-y.

21. Cao Y, Wang W, Liu Y, Cotter C, Zhou H, Zhu G, et al. The increasing importance of Plasmodium ovale and Plasmodium malariae in a malaria elimination setting: an observational study of imported cases in Jiangsu Province, China, 2011-2014. Malaria journal 2016;15:459; doi:10.1186/s12936-016-15042. http://www.ncbi.nlm.nih.gov/pubmed/27604629.

22. WHO. Clinical management of severe acute respiratory infection when novel coronavirus (nCoV) infection is suspected: interim guidance. 2020.

23. WHO. Pneumonia of unknown cause-China. Jan 5, 2020. 2020.

24. WHO. Novel coronavirus-China; emergencies preparedness, response. Jan 12. 2020. 2020.

25. Wang KW, Gao J, Wang H, Wu XL, Yuan QF, Guo FY, et al. Epidemiology of 2019 novel coronavirus in Jiangsu Province, China after wartime control measures: A population-level retrospective study. Travel Med Infect Dis. 2020;35:101654; doi:10.1016/j.tmaid.2020.101654. http://www.ncbi.nlm.nih.gov/pubmed/32268195.

26. Lee H, Lee H, Song KH, Kim ES, Park JS, Jung J, et al. Impact of Public Health Interventions on Seasonal Influenza Activity During the SARS-CoV-2 Outbreak in Korea. Clinical infectious diseases: an official publication of the Infectious Diseases Society of America. 2020; doi:10.1093/cid/ciaa672. http://www.ncbi.nlm.nih.gov/pubmed/32472687.

27. Rahman M, Sobur M, Islam M, Toniolo A, Nazir K. Is the COVID-19 pandemic masking dengue epidemic in Bangladesh? Journal of advanced veterinary animal research. 2020;7(2):218-9. doi:10.5455/javar.2020.g412. 
28. Sakamoto H, Ishikane M, Ueda P. Seasonal Influenza Activity During the SARS-CoV-2 Outbreak in Japan. JAMA. 2020;323 19:1969-71. doi:10.1001/jama.2020.6173.

29. Ehrenberg J, Zhou X, Fontes G, Rocha E, Tanner M, Utzinger J. Strategies supporting the prevention and control of neglected tropical diseases during and beyond the COVID-19 pandemic. Infectious diseases of poverty. 2020;9 1:86; doi:10.1186/s40249-020-00701-7.

30. Liu Z, Shen T, Wei D, Yu Y, Huang D, Guan P. Analysis of the Epidemiological, Clinical Characteristics, Treatment and Prognosis of Human Brucellosis During 2014-2018 in Huludao, China. Infection and drug resistance. 2020;13:435-45; doi: 10.2147/idr.S236326.

31. Hogan A, Jewell B, Sherrard-Smith E, Vesga J, Watson O, Whittaker C, et al. Potential impact of the COVID-19 pandemic on HIV, tuberculosis, and malaria in low-income and middle-income countries: a modelling study. The Lancet Global health. 2020;8(9):e1132-e41. doi:10.1016/s2214$109 \times(20) 30288-6$.

32. Liu Y, Hsiang M, Zhou H, Wang W, Cao Y, Gosling R, et al. Malaria in overseas labourers returning to China: an analysis of imported malaria in Jiangsu Province, 2001-2011. Malar J. 2014;13:29. doi:10.1186/1475-2875-13-29.

33. Coelho A, García-Díez J, Góis J, Rodrigues J, Coelho A. Farm practices and risk factors which influence the high prevalence of brucellosis in small ruminant flocks in Northeast Portugal. Vet Ital. 2019;55(4):355-62. doi:10.12834/Vetlt.1162.6419.2.

34. Trájer A. Plasmodium vivaxThe changing risk patterns of malaria in Greece due to climate change. International journal of environmental health research. 2020:1-26; doi: 10.1080/09603123.2020.1793918.

\section{Figures}




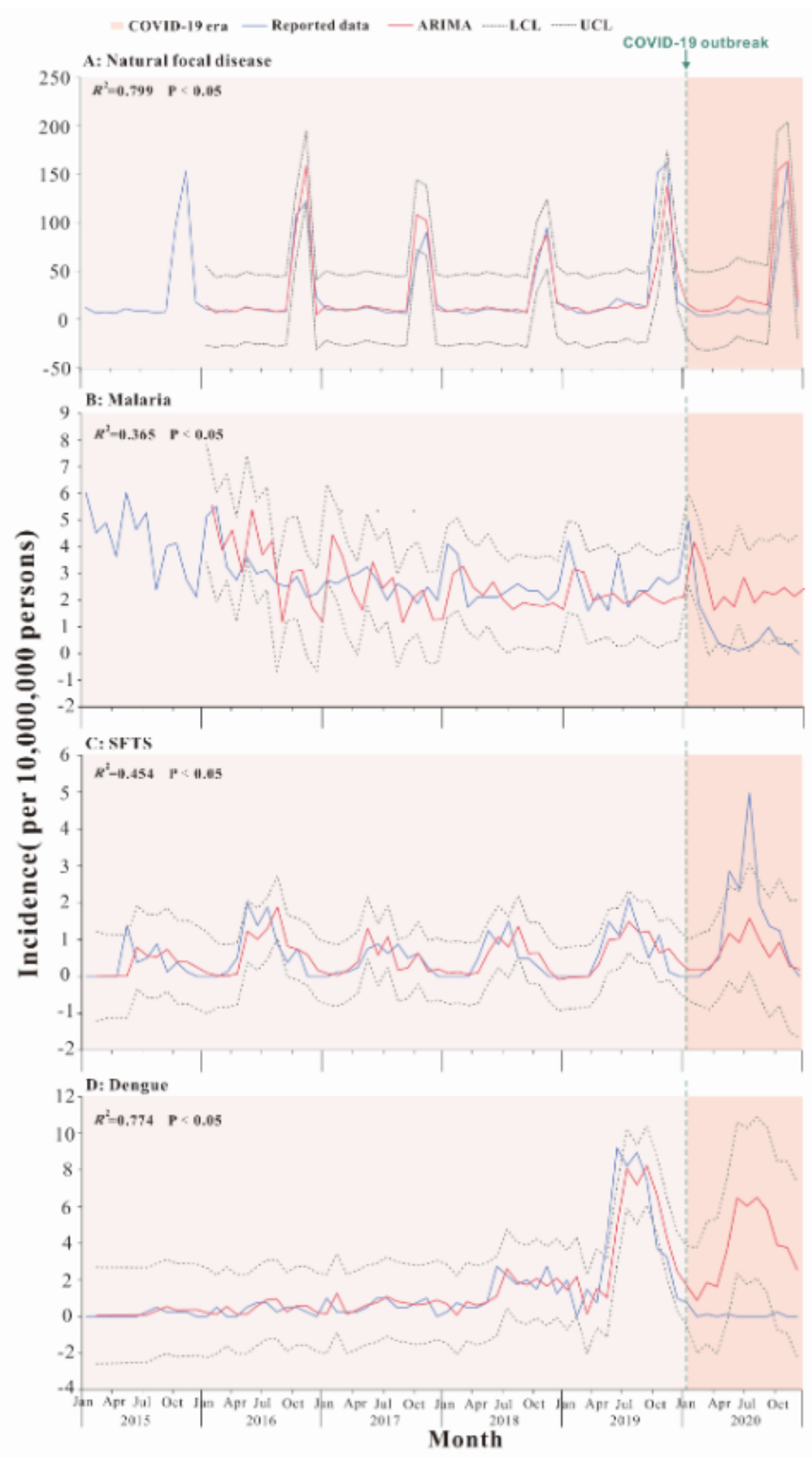

\section{Figure 1}

The incidence trend and curve fitting results of natural focus disease, malaria, SFTS and dengue. JiangsuProvince, China, 2015-2020. (A) Natural focus diseases; (B) Malaria; (C) SFTS; (D) Dengue. 


\section{A: Brucellosis}

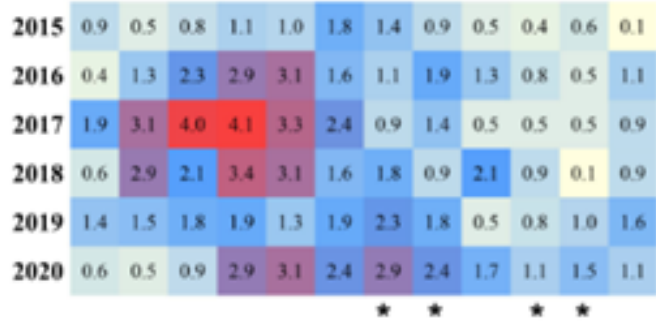

\section{C: HFRS}

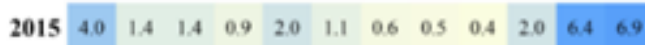
$\begin{array}{lllllllllllll}2016 & 4.1 & 1.4 & 1.5 & 1.8 & 2.1 & 2.8 & 1.5 & 1.1 & 0.9 & 2.5 & 9.9 & 11.7\end{array}$ $\begin{array}{lllllllllllll}2017 & 4.3 & 2.9 & 2.6 & 2.3 & 3.4 & 3.3 & 1.8 & 1.1 & 0.8 & 2.1 & 13.4 & 9.2\end{array}$ $\begin{array}{lllllllllllll}2018 & 3.1 & 0.9 & 1.5 & 1.4 & 3.3 & 2.5 & 1.4 & 1.0 & 0.3 & 3.4 & 8.5 & 6.7\end{array}$

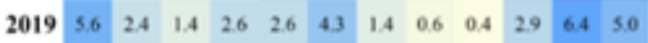
$\begin{array}{lllllllllllll}2020 & 3.0 & 1.5 & 1.0 & 1.4 & 1.7 & 1.1 & 1.1 & 0.6 & 0.5 & 2.0 & 6.0 & 3.0\end{array}$

\section{E: Dengue}

$\begin{array}{lllllllllllll}2015 & 0 & 0 & 0 & 0 & 0 & 0 & 0.3 & 0.5 & 0.3 & 0.3 & 0.3 & 0\end{array}$ $\begin{array}{lllllllllllll}2016 & 0 & 0.5 & 0 & 0 & 0.5 & 0.8 & 0.8 & 0.3 & 0.5 & 0.5 & 0.3 & 0\end{array}$ $\begin{array}{lllllllllllll}2017 & 1.0 & 0.3 & 0.3 & 0.3 & 0.5 & 1.0 & 1.0 & 0.5 & 0.5 & 0.8 & 1.0 & 0\end{array}$ $\begin{array}{lllllllllllll}2018 & 0.2 & 0.8 & 0.5 & 0.5 & 0.8 & 2.8 & 23 & 1.8 & 2.0 & 1.5 & 2.8 & 1.3\end{array}$

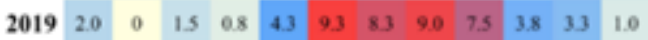
$\begin{array}{lllllllllllll}2020 & 0.7 & 0 & 0.1 & 0 & 0.1 & 0 & 0 & 0 & 0 & 0.2 & 0 & 0\end{array}$

\section{G: Tsutsugamushi}

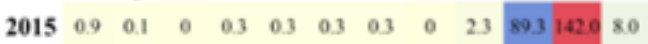

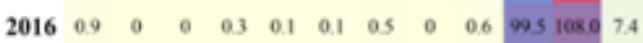
$\begin{array}{lllllllllllll}2017 & 0.4 & 0.4 & 0.3 & 0.3 & 0.6 & 0 & 0.4 & 0.5 & 1.0 & 56.4 & 72.1 & 2.9\end{array}$ $\begin{array}{lllllllllllll}2018 & 0.5 & 0.4 & 0.1 & 0 & 0.4 & 0.1 & 0.8 & 0.3 & 0.8 & 47.2 & 82.0 & 5.0\end{array}$ $\begin{array}{lllllllllllll}2019 & 0.6 & 0.1 & 0 & 0.1 & 0.3 & 1.0 & 0.4 & 0.3 & 1.4 & 14201496 & 7.8\end{array}$ $\begin{array}{lllllllllllll}2020 & 1.1 & 0.1 & 0.1 & 0.2 & 0.2 & 0.2 & 0.9 & 0.5 & 0.9 & 61.4 & 152.4 & 8.3\end{array}$

Jan Feb Mar Apr May Jun Jul Aug Sep Oet Nov Dec

\section{B: Malaria}

\begin{tabular}{l|l|l|l|l|l|l|l|l|l|l|l|l}
2015 & 5.3 & 3.6 & 33 & 2.9 & 4.5 & 3.1 & 3.8 & 1.4 & 2.8 & 3.1 & 1.6 & 1.8
\end{tabular} \begin{tabular}{l|llllllllllll}
2016 & 40 & 45 & 29 & 2.1 & 3.0 & 2.3 & 2.4 & 2.1 & 1.8 & 1.9 & 1.3 & 1.9
\end{tabular}

\begin{tabular}{lllllllllllll|}
2017 & 1.6 & 1.6 & 1.9 & 25 & 2.4 & 2.0 & 1.6 & 1.5 & 1.3 & 1.6 & 1.6 & 1.4
\end{tabular} \begin{tabular}{llllllllllllll|}
2018 & 3.2 & 3.0 & 0.5 & 1.0 & 1.6 & 1.4 & 1.9 & 1.6 & 2.1 & 1.5 & 1.1 & 1.6
\end{tabular} \begin{tabular}{l|l|l|l|l|l|l|l|l|l|l|l|l}
2019 & 3.7 & 1.9 & 1.5 & 1.6 & 1.6 & 3.1 & 1.3 & 2.3 & 2.1 & 2.1 & 2.5 & 2.4 \\
\hline
\end{tabular} $\begin{array}{lllllllllllll}2020 & 5.0 & 1.9 & 1.1 & 0.4 & 0.2 & 0.1 & 0.2 & 0.5 & 1.0 & 0.4 & 0.4 & 0\end{array}$ ********** D: SFTS

$\begin{array}{llllllllllllll}2015 & 0 & 0 & 0 & 0 & 1.4 & 0.4 & 0.5 & 0.9 & 0.1 & 0.4 & 0.1 & 0\end{array}$ \begin{tabular}{lllll|l|l|l|l|l|lll}
2016 & 0 & 0 & 0.1 & 0.5 & 20 & 1.4 & 1.9 & 0.9 & 0.4 & 0.8 & 0 & 0
\end{tabular} $\begin{array}{lllllllllllll}2017 & 0 & 0.1 & 0.1 & 0.3 & 0.8 & 0.9 & 0.6 & 0.9 & 0.5 & 0.6 & 0.3 & 0\end{array}$ $\begin{array}{lllllllllllll}2018 & 0 & 0 & 0 & 0.5 & 1.3 & 0.9 & \text { is } & 0.5 & 0.5 & 0.3 & 0 & 0\end{array}$ $\begin{array}{lllllllllllllll}2019 & 0 & 0 & 0 & 0.6 & 1.5 & 1.1 & 2.1 & 1.3 & 0.5 & 1.1 & 0.1 & 0\end{array}$ $\begin{array}{lllllllllllll}2020 & 0 & 0 & 0.2 & 0.5 & 2.9 & 2.4 & 5.0 & 20 & 1.4 & 1.2 & 0.4 & 0\end{array}$

\section{F: Rabies}

\begin{tabular}{llllllll|l|llll}
2015 & 0.4 & 0 & 0.3 & 0.5 & 0.4 & 0.3 & 0.3 & 1.0 & 0.4 & 0.4 & 0.3 & 0.3
\end{tabular} \begin{tabular}{llllllllll|llll}
2016 & 0.1 & 0.5 & 0.5 & 0 & 0.6 & 0.5 & 0.3 & 0.1 & 1.1 & 1.1 & 0.4 & 0.3
\end{tabular} \begin{tabular}{llllll|llllllll}
2017 & 0.3 & 0.1 & 0.4 & 0 & 0.8 & 0 & 0.1 & 0 & 0.3 & 0.3 & 0.4 & 0.1
\end{tabular} \begin{tabular}{lllllll|l|l|l|l|l|l}
2018 & 0 & 0.3 & 0 & 0.4 & 0 & 0.5 & 0 & 0.4 & 0.3 & 0.6 & 0.3 & 0.1
\end{tabular} $\begin{array}{lllllllllllll}2019 & 0.1 & 0.3 & 0 & 0.1 & 0.1 & 0.1 & 0.5 & 0.3 & 0 & 0.3 & 0.3 & 0\end{array}$ $\begin{array}{lllllllllllll}2020 & 0.4 & 0.2 & 0.4 & 0 & 0 & 0 & 0.4 & 0.2 & 0.4 & 0.1 & 0 & 0.1\end{array}$ H: JE

\section{Month}

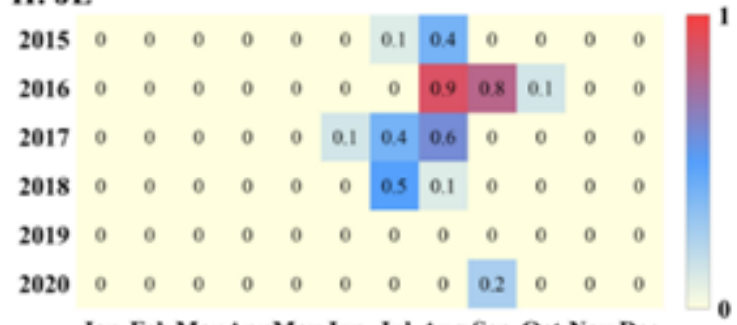

Jan Feb Mar Apr May Jun Jul Aug Sep Oet Nov Dec

\section{Figure 2}

Month distribution of natural focus diseases, Jiangsu Province, China, 2015-2020. (A) Brucellosis; (B) Malaria; (C) HFRS; (D) SFTS; (E) Dengue; (F) Rabies; (G) Tsutsugamushi; (H) JE. 


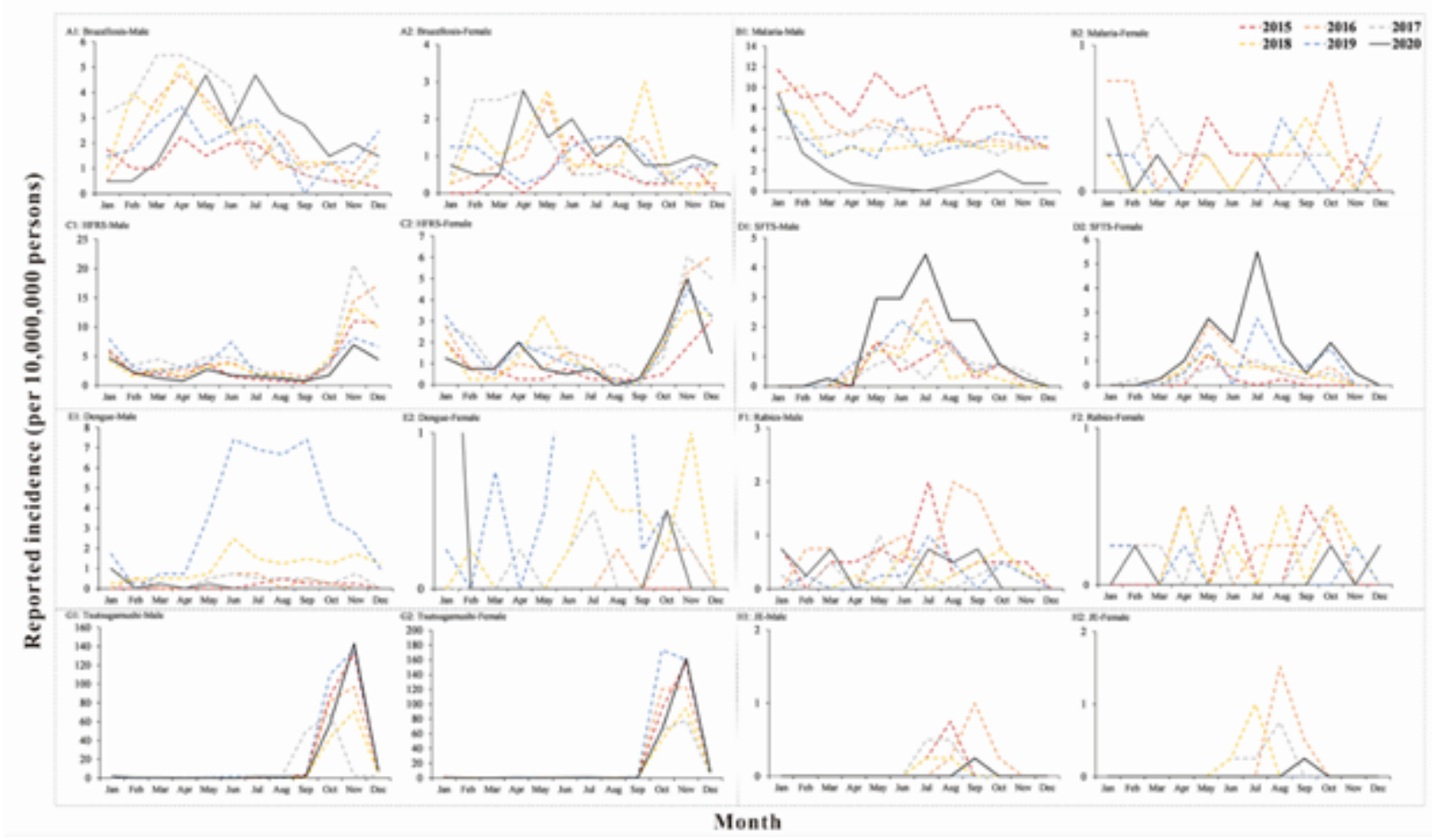

Figure 3

Gender distribution of natural focus diseases, Jiangsu Province, China, 2015-2020. (A) Brucellosis; (B) Malaria; (C) HFRS; (D) SFTS; (E) Dengue; (F) Rabies; (G) Tsutsugamushi; (H) JE.

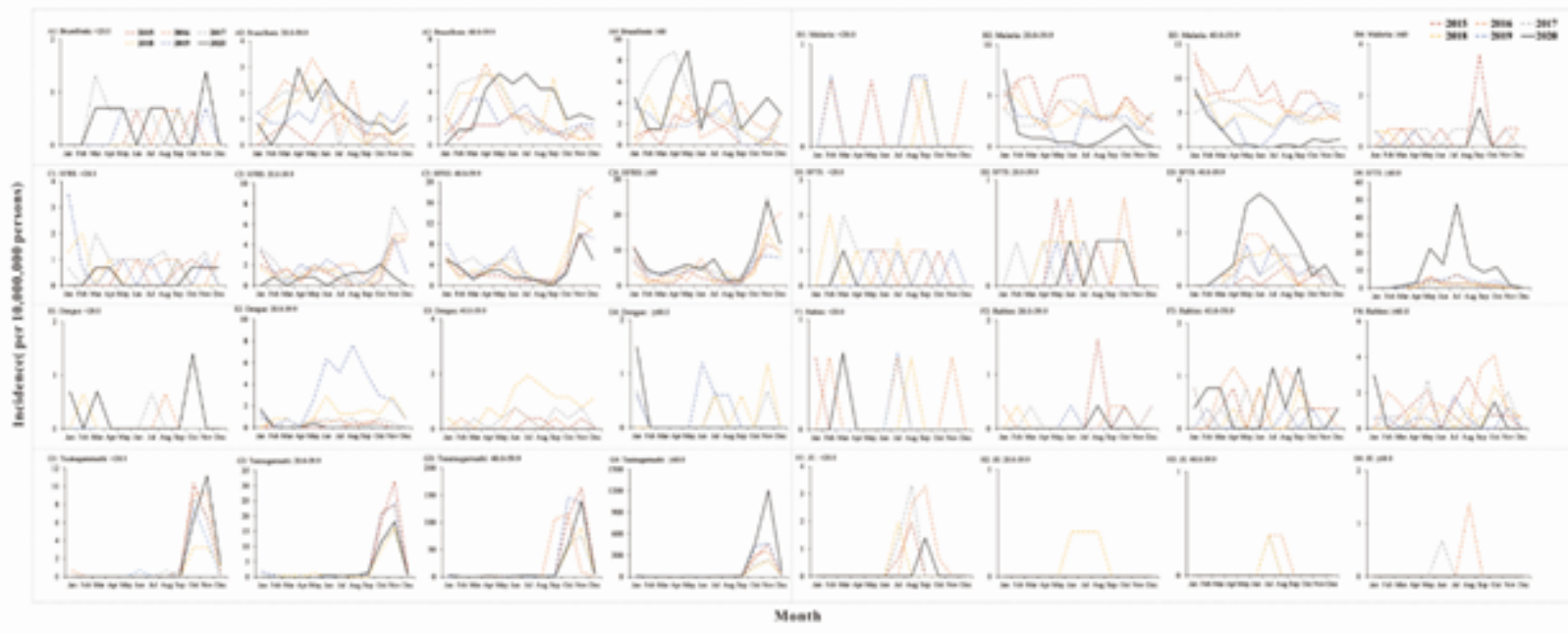

Figure 4

Age distribution of natural focus diseases, Jiangsu Province, China, 2015 - 2020. (A) Brucellosis; (B) Malaria; (C) HFRS; (D) SFTS; (E) Dengue; (F) Rabies; (G) Tsutsugamushi; (H) JE. 


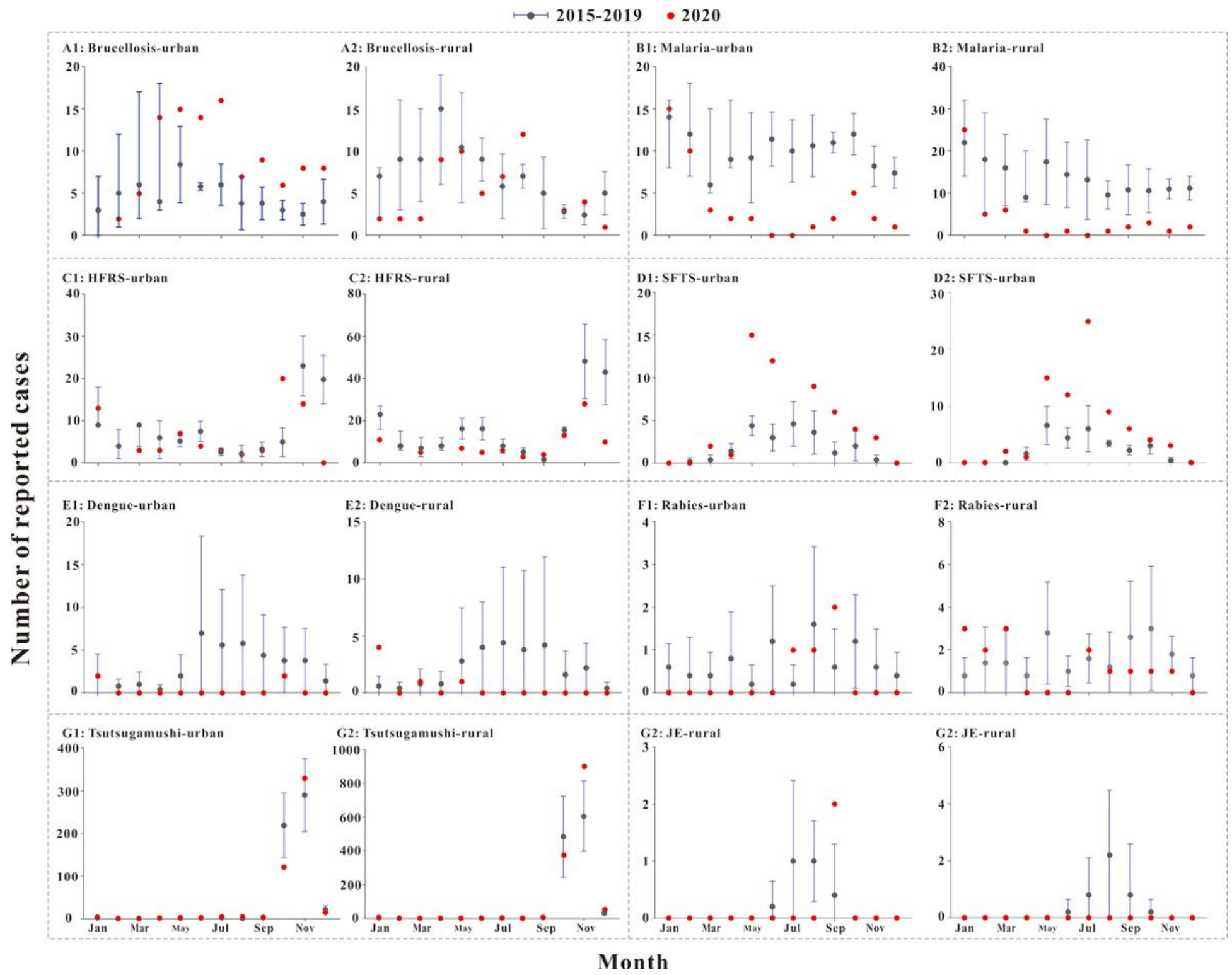

Figure 5

Urban and rural distribution of natural focus diseases, Jiangsu province, China, 2015 - 2020. (A) Brucellosis; (B) Malaria; (C) HFRS; (D) SFTS; (E) Dengue; (F) Rabies; (G) Tsutsugamushi; (H) JE.

\section{Supplementary Files}

This is a list of supplementary files associated with this preprint. Click to download.

- Graphicalabstract.jpg 